\title{
A LOGIC FUZZY MODEL FOR EVALUATION OF THE RAILWAY STATION'S PRACTICE CAPACITY IN SAFETY OPERATING CONDITIONS
}

\author{
F. CORRIERE ${ }^{1}$, D. DI VINCENZO ${ }^{2}$, M. GUERRIERI ${ }^{3}$
}

\begin{abstract}
The practice capacity of a railway junction depends, in addition to the effective operation's conditions, by the potential risk factors related to the design plan of the railway station. With the aim of an approach based on the "fuzzy sets" it is possible to determine the numeric value of the practice capacity by the logic - qualitative relations between the features of the railway junction and the potential risk factors. This methodology permits to try out the absolute value of a suitable vector $\beta$, (less then the unit) for the utilization of the theoretic capacity in conditions of maximum reliability of the system related to the aspect of safety (technique "fail safe").
\end{abstract}

Key words: railway stations, practice capacity, fuzzy set, operative conditions.

\section{INTRODUCTION}

The railway circulation technique has the primary target to study and define the measures to allow the trains circulation even in safety conditions, optimising the reliability of the system by the appraisal of its components and, in particular, of those accountable of the circulation inside the station where the higher complex manoeuvres are executed. This level of reliability must be maintained in all the phases of system's operations by specific and programmed maintenance interventions as recently exposed by the authors [1].

The greater difficulty in the appraisal of the system's reliability is the corrected location of the probability of "breakdown"; this consideration has permitted also the spread of the so-called "systems fail-safe" (sure in breakdown case), which, in atypical operative situations, leads, generally, to more restrictive conditions of employ for the degraded level of service.

The "fail-safe" technique suggests the opportunity, to define, beside the phase of the infrastructure planning, on the base of the analysis and preventive appraisal of the risk, a safety margin, previewing a "coefficient of practical use" less then the unit defined as

1 Associate Professor, Faculty of Architecture, University of Palermo, Italy, Departement of Energia, viale delle Scienze Ed.9, Palermo 90100, Italy, e-mail: ferdinando.corriere@unipa.it

2 Adjunct Professor at University of Palermo, Italy, Departement of Energia, viale delle Scienze Ed.9, Palermo 90100, Italy, e-mail: dariodv@tiscali.it

3 Researcher, University of Enna "Kore" - Adjunct Professor at University of Palermo, Italy, e-mail: marco.guerrieri@tin.it, (Corresponding Author) 
the fraction between the practice capacity of the system and the theoretic one; the inverse of such rapport (greater of the unit) can be meant like "safety factor" in reference to corrected system's functionality even in presence of anomalies of the devices.

\section{THEORETIC CAPACITY OF A RAILWAY JUNCTION}

Models for evaluations the capacity of railway networks are required in the planning of new railway infrastructures and in the track operation that requires a diligent coordination of infrastructure, timetables and traffic control [2], [3]. Also, railway infrastructure, traffic management and dynamic train movement have an important impact on energy consumption [4]. This paper presents a model for estimation the capacity, delay and safety sustainability in a railway junctions. This evaluation model uses the fundamental phases of a method, published in 2004 [5] and other previous studies [6] [7] [8] concerning railway lanes. These experiences permit the appraisal of theoretic capacity with the aid of a mathematical model related to the real conditions of system's, to its characteristics and yet to the probabilities of delay in the arrivals of the trains, and therefore of interference between them. The capacity of every junction's path can be calculated using a formula derived from the classic expression used for theoretical capacity of the station's path $\mathrm{P}_{\mathrm{T}, \mathrm{it}}$ :

$$
\mathrm{P}_{\mathrm{T}, \mathrm{it}}=\sum_{\mathrm{i} \in \mathrm{N}} \mathrm{n}_{\mathrm{i}}+\frac{\mathrm{T}-\sum_{\mathrm{i} \in \mathrm{N}} \mathrm{n}_{\mathrm{i}} \mathrm{t}_{\mathrm{i}}}{\mathrm{t}}
$$

in which:

$\sum_{i \in \mathrm{N}} \mathrm{n}_{\mathrm{i}}=$ number of the trains that cover the path $i t$ in the time of reference $\mathrm{T}$;

$\mathrm{T}=$ reference time;

$\sum_{\mathrm{i} \in \mathrm{N}} \mathrm{n}_{\mathrm{i}} \mathrm{t}_{\mathrm{i}}=$ total times employed in the system by all the movements that are carried out on the path it;

$\mathrm{N}=$ set of the trains on the considered path in time of reference;

$\mathrm{t}=$ regular occupancy time of the junction by the generic train of the same velocity's class of reference.

From (1), in order to take into account of the possible interferences endured by the trains in covering the assigned path, the numerator of the fraction at the second member is modified as follows:

$$
P_{T, i t}=\sum_{i \in N} n_{i}+\frac{T-\left(\sum_{i \in(N-M)} n_{i} t_{i}+\sum_{i \in M} n_{i} t_{\text {occ }, i}\right)}{t}
$$

Where $\mathrm{M}$ is the set of trains on the considered path that can endure interferences. 
Consequently, it is also defined the set N-M of the trains that has no any probability to endure interferences and for which, evidently, isn't considered anomalous time of occupation. The occupation's time of a specific path by a train is called regular, if the train must only observe the times of path's predisposition and of running on the same; it is anomalous, otherwise, if, train endures interferences on its path due to other trains that cover paths not independent from the first one. The reason of anomalous occupation can be due only by the outside arrival (in particular in delay) of interfering trains. Holding therefore account of the $P_{i j}$ probability that a train $i$ endures interference from a train $j$, the occupation's time of the path by the train $i$ can be expressed from:

$$
\mathrm{t}_{\mathrm{occ}, \mathrm{i}}=\mathrm{P}_{\mathrm{ij}} \cdot \tau_{\mathrm{i}}+\left(1-\mathrm{P}_{\mathrm{ij}}\right) \cdot \mathrm{t}_{\mathrm{i}}
$$

where:

$\tau_{\mathrm{i}}=$ anomalous time of path's occupation by train $\mathrm{i}$

$t_{i}=$ time of regular path's occupation by train $i$.

In short, the medium occupation time by a train in a definite path is as well proximal to the time of regular occupation how small is probability that the train endures interference; in fact from the (3):

$\mathrm{t}_{\mathrm{occ}, \mathrm{i}}=\mathrm{t}_{\mathrm{i}}$ for $\mathrm{P}_{\mathrm{ij}}=0$

$\mathrm{t}_{\mathrm{occ}, \mathrm{i}}=\tau_{\mathrm{i}}$ for $\mathrm{P}_{\mathrm{ij}}=1$

To determine the regular time of occupation, it is enough to sum, taking as an example a train in arrival, the necessary time for path's construction (until the manoeuvres to free way of marks system's protection), the interval of time from the moment in which the path is formed to the one of the effective arrival of the train to protection's marks, the physical running time until the stop and, finally, the dwell time. Similarly it's possible to calculate the times of regular occupation for trains in departure or in passage. Replacing in (2) at the place of $\mathrm{t}_{\mathrm{occ}, \mathrm{i}}$ the expression (3), by some algebraic passages and extending the sum to all it independent paths of the junction, we obtain the definitive expression of model for the calculation of the theoretical capacity of the railway junction:

$$
P_{T, N}=\sum_{i t}\left[\sum_{i \in N} n_{i}+\frac{T-\left(\sum_{i \in N} n_{i} t_{i}+\sum_{i \in M} n_{i} P_{i j}\left(\tau_{i}-t_{i}\right)\right)}{t}\right]
$$

where $\mathrm{P}_{\mathrm{ij}}$ indicates the probability that the generic train of class $\mathrm{i}$ endures interferences by any number of interfering trains $\mathrm{j}$. About the $\mathrm{P}_{\mathrm{ij}}$ term of the (3), it can be calculated integrating, in an opportune interval of time, a suitable function of density of probability of arrival to the junction; experimentally it has-been found that the function that better acquits to the range is the following log-normal [9]: 


$$
f_{x}(x)=\frac{1}{x \cdot \sigma \cdot \sqrt{2 \pi}} \cdot \exp \left[\frac{1}{2} \cdot\left(\frac{\ln x-\mu}{\sigma}\right)^{2}\right]
$$

in which $\mu$ and $\sigma$ are respectively the arithmetic mean and the standard deviation of the distribution $\log$ - normal, they are expressed analytically:

$(5 \mathrm{~b} / \mathrm{c})$

$$
\mu=\ln \mu_{(\mathrm{x})}-\frac{1}{2} \ln \left(1+\frac{\sigma_{(\mathrm{x})}^{2}}{\mu_{(\mathrm{x})}^{2}}\right)
$$

$$
\sigma^{2}=\ln \left(1+\frac{\sigma_{(\mathrm{x})}^{2}}{\mu_{(\mathrm{x})}^{2}}\right)
$$

$\mu_{(\mathrm{x})}$ and $\sigma_{(\mathrm{x})}$ are respectively the values of the arithmetic mean and the standard deviation assumed by variable $\mathrm{x}$.

The probability that a train $\mathrm{j}$ interferes with a train is given by the probability that the two events "arrival to the junction" are contemporary, and therefore in analytical terms results:

$$
P_{i, j}=\int_{T_{A}-t_{j}}^{T_{B}} f_{j} \cdot\left(\int_{t}^{t+t_{j}} f_{i} d t\right) d t
$$

where:

$\mathrm{T}_{\mathrm{A}}, \mathrm{T}_{\mathrm{B}}=$ extremes of the interval of the function of arrivals distribution;

$f_{i}, f_{j}=$ probability density functions of arrival to the junction of the trains $i$ and $j$;

$t_{j}=$ regular time of occupation of the interfering train.

Really the simple product of the probability to endure interference for the number of interfered with trains is valid only when the timetables of arrival of the interfered train and of the interfering one are always cadenced with the same interval of time; in fact the integral (6) assumes various values in dependence of the integration ends, those depending on the "relative positions" of the distribution functions on the temporal scale. Such functions of distribution of type log - normal must be positioned in the temporal scale with respect to the difference between the programmed arrival timetables of the interfering train and the one potentially interfered with (Figure 1). The distribution log-normal, like all the functions of distribution, spreads to 0 for $\mathrm{x}$ tending to infinite and assumes value 0 for $\mathrm{x}=0$, that is equivalent to assume that a train cannot arrive in advance; so the inferior end of integration of the external integral should be 0 ; but the train $\mathrm{j}$ that arrives before the 0 (instant $\mathrm{T}_{\mathrm{A}}$ of arrival of the interfered train) of a less or equal time to $t_{j}$ it could interfere however with the train $\mathrm{I}$; for this reason the inferior end of integration of the external integral is $T_{A}-t_{j}$.

The choice of the advanced end coincides with the one of the maximum delay that is the one generally considered; the asymptotic course of the function of distribution 
means that always smaller probabilities of arrival exist to increasing of the delay and that a train can arrive with a delay boundary infinite; it is assumed therefore, like the hypothetical maximum delay, the one which is not exceeded by $90 \%$ of the trains: the distribution function comes integrated between the 0 and the value in correspondence of which the area subtended from the same function it is equal to $90 \%$ of the arrivals. Therefore the supreme end of integration changes every time according to the class of trains considered like interfering. Different classes of trains generally have, in fact, different functions of distribution of the arrivals.

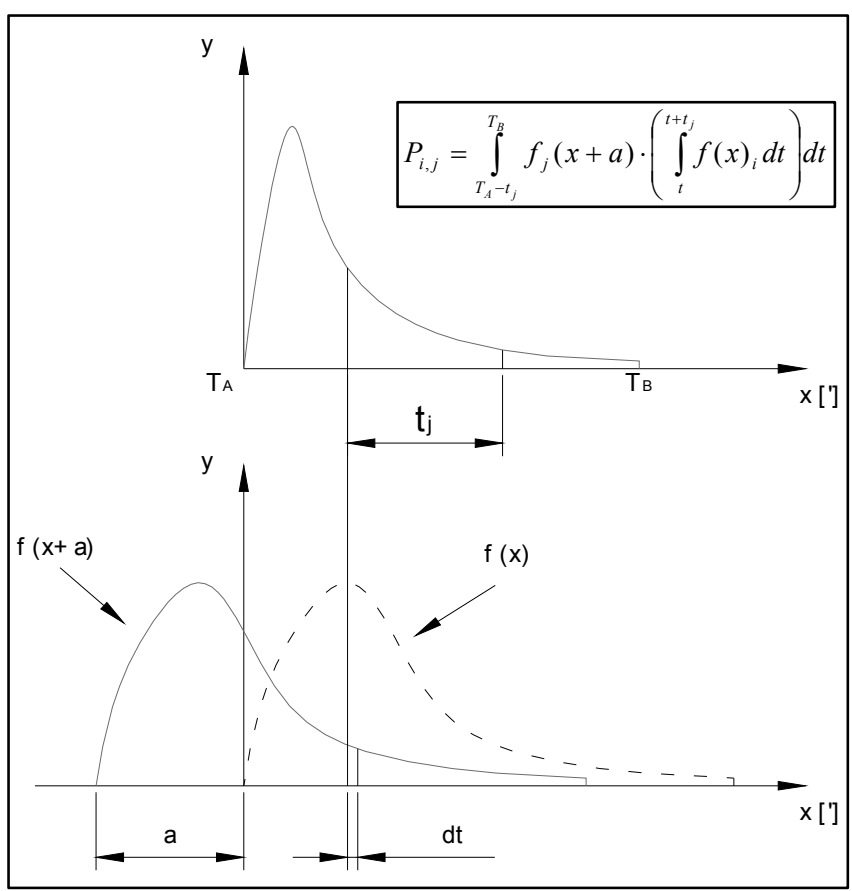

Fig. 1. Distribution of the arrival's probabilities at the junction of the trains $i$ and $j$ and calculation of the interference endured from the train $i$ because of $j$.

\section{JUNCTION'S PRACTICE CAPACITY AND REASONS OF ACCIDENT'S FREQUENCY}

The previous expression (4) defines the theoretic capacity of the railway junction. The practice capacity could be obtained multiplying the first one for the module of an opportune vector $\boldsymbol{\beta}$ less then the unit, its components vectors in $\mathfrak{R}_{\mathrm{m}}$ correspond to anomalies in the operability of the devices to direct the trains and, generally, to other deficiencies attributable to the station's devices or to the management's procedures. Since the capacity of a line or of a railway junction depends both from the technology system's configuration and from the employ's modalities by trains, the functionality of a line 
is strictly related to the characteristics of the protection's system, to the timetable's organization and to the abilities to shunt the traffic in the junctions. Each of the upper variables, as it will be looked in advance, determines, in more or less directed shape the so-called potential factors of risk for the safety in the system's operations. The safety is, then, tied to the probability of anomalous occupations of the railroads, to the reliability of the single elements of the system, to the procedures of employment and, finally, to the "human factor", both in standard situations that in degraded ones [10]. In the railway planning and, in particular, in the modernizing interventions of the network, strategic importance covers the function of shunting the traffic flows, to guarantee adapts performance's standards to the entire system, under the profile of the economy, the efficiency and of the safety in the management [1], [11]. For the safety and, therefore, for the accident's frequency, great attention must be turned to the so-called potential accidents, that are, over all, those anomalous situations that can generate an increase in the level of localized or diffused risk. Not only specific elements of danger related to the infrastructure's system, but also the same configurations of management's procedures play a relevant responsibility on the quality and on the safety; first of all the decisive "human factor" that always represents the co primary reason and, often decisive of the accident's frequency phenomena.

The presence of potential risk's factors related to the railway's activity, suggests the need of an adequate methodology of analysis that permits to define the numerical value of a index of employ as a corrective factor for theoretical capacity to obtain a more adequate value of practical capacity under the profile of the safety of the exercise. Such index of employ must hold account of the weights of the numerous factors of risk, in relation to the effective configuration of the station's plan and to the other variable characterizing the exercise. Many of the factors taken in consideration are often of qualitative nature and badly lend themselves to quantification/evaluation by means of classic procedures, of cardinal type. Often some of these criteria can be only expressed by means of judgment's value for their nature subjective and therefore vague, indefinite and from the uncertain borders. The explicit acknowledgment of the vague nature and indefinite of many value's judgments - based on the natural language - is at the bottom of the methodological development that we want to introduce and that makes reference to logic polyvalent and to the theory of the fuzzy sets [12]. About the analysis of the "reasons associated" to the accident's railway frequency, we have kept in account 50 possible reasons of accidents on line or in the railway stations. Because we need to determine one use index related to the risk, it has been eliminate from the database the records containing less than the five light wounded (situations practically "sure").

It was also eliminated from the database all the records not containing any wounded or mortal event, because not explicative for the analysis of the reasons associated to the risk of accident. To be able to manage in optimal way the data and considered that some events tied to the associate reasons can be considered of extraordinary nature, the number of records of the database has been ulterior reduced by eliminating those 
data tied to associate reasons that take place very rarely in the interval of time taken in consideration (three years from the 01.01.2001 to 31.12.2003).

In particular, the number of associated reasons has been limited, thinking it meaningful for the implementation of the model, to the following:

- Inattention travellers and staff FS (Inatt.);

- Undue cross of the railroads (Cross);

- Irregular movements of manoeuvre (Manoeuvre);

- Undue climb/downhill from train (CD);

- Persons near the railway not at a safety distance (Distance);

- Anomalies regarding the operating staff of job (Yards).

\section{THE INFERENTIAL FUZZY MODEL TO DEFINE THE CAPACITY'S UTILIZATION COEFFICIENT}

Norms UIC impose to the Countries members to record like accidents those events that have involved the dead of one or more persons and/or the wounding with prognosis more than 14 work days of one or more persons and/or an interruption of the circulation advanced to the six hours and/or damages estimated in more than $€ 10.330$. According to such classification the accidents can be:

- typical: accidents more closely connected to the system railway; they comprise collisions between trains or routable, derailments, accidents to the passages to street level, fires to edge, etc.;

- atypical: accidents that have only interested persons; they comprise the fall of persons from the trains, damages endured during climb or the reduction from the railway carriages, suspected suicides, etc.

The database, which can be used for the implementation of the inferential model, is the System Bank Data Safety of the railway circulation (in the following indicated like BDS) of RFI SpA (Italian Railway Net). Beyond describing UIC accidents, RFI also records all those accidents that have not caught up the indicated thresholds (called "Accidents light ") and, above all, all those potentially dangerous events that, even without consequences, could degenerate in accidents (defined "Situations anomalous"). In order to supply a dimension of the inserted events, the BDS records monthly 1.000 events on an average, of which approximately the $2 \%$ "Accidents UIC", approximately $18 \%$ they are "light Accidents" and remaining $80 \%$ are "anomalous Situations".

In particular the BDS works in such a way that every reached information is inserted in system second one "Tree of the reasons" that codifies events leaving from the macro typology of the accident (for example: "Typical" accident in circulation) following for several coppers of inferior level: Macro classification (for example: collision, derailment, other), it classifies (for example: collision between trains running in opposite sense), the anomalous situation that has determined the event (for example: SPAD - Undue exceed of signalling disposed to stop), one Primary reason (inobservances of the regulations) and finally one Secondary reason (for example: distraction). 
The Inferential Fuzzy system (SIF) is a process that concurs to generate a system of data of output leaving from data of input and using Fuzzy Logic. The process leaves from the functions of membership, continues by operating logical described before and by means of the rules of type "if-then", about which it will be discussed in the continuance [13]. In the present job the inferential system is used to modelling the tie existing between a system of data of input/output, constituted respectively from a system of reasons associated to the accident's frequency railway and from a use index that it supplies, for a such planning typology of the station, the degree of correction of theoretical capacity to the optimisation of the exercise safety. In fig. 2 is shown a general outline of one simple inferential fuzzy system composed by $n$ functions of input, from $r$ rules if-then and by a system of $m$ functions of output.

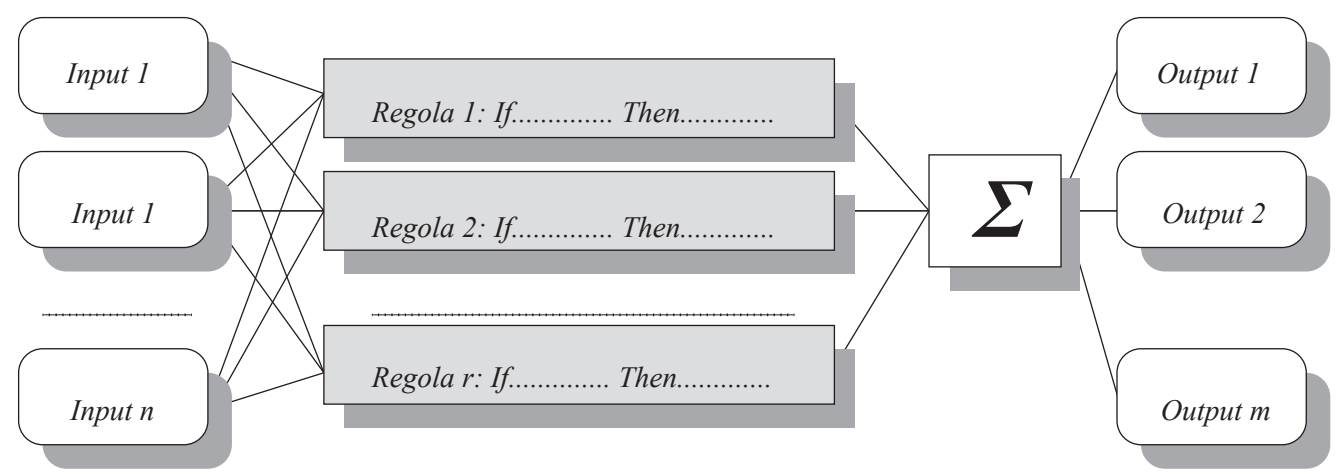

Fig. 2. Inferential Fuzzy system.

The flow of information in the model starts from left towards right and to the out of the system the data are unfazed and rendered crisp.

The system of parallel rules is a fundamental aspect of the inferential fuzzy systems; in fact it is possible, using contemporary more rules, to pass progressively between regions where the behaviour of the system is managed by a rule rather than another.

The inferential fuzzy process is subdivided in 5 subsequent steps:

1) fazed of the variable ones of income;

2) application of operating fuzzy the AND/OR in the antecedent ${ }^{4}$

3) implication from the antecedent to consequent;

4) aggregation of the consequent one through it arranges of rules;

5) phase of unfazed.

The first step consists in determining the degree of belonging to every fuzzy set of the several one input considered by the appropriated ones functions of membership.

${ }^{4}$ It is defined an antecedent part of a inferential system as the relative part to the fazed of the data of input and first part of the rules (if... or... and). It is defined consequent the relative phase to the second part of rules (....then) and to the unfazed. 
The value of input is always a numerical value of type crisp opportunely defined in interval $[0,1]$, that is standardized. For the case in argument, the variables of reference are those exposed at the end of the previous paragraph.

The phase of fazed, that consists in the search and definition of the membership function. For each of the variable over listed, we have considered three functions related to the degree of memberships of the found numerical value. One time the functions of membership are known, we can also know, for each rule, the degree with which every part of antecedent is satisfied. If the antecedent of a given rule is composed from more than one part, the operating fuzzy are used to obtain a numerical fuzzy value that can represent the whole antecedent. The data of income for the operating fuzzy consist in two or more values of membership, deriving from the fazed input variables. The output is a single value. The operating logical more used is AND/OR. The operator AND involves the mathematical operations of min (minimal) and prod (algebraic product), the operator OR is put into by the operations of max. (maximum) and of prob. (probabilistic) better known like algebraic sum. Before passing to step 3, it's necessary to pay much attention to the well estimate weights of the rules if-then. Every rule, in fact, can be controlled by one factor of amplification (or weight) that consists in a number comprised between 0 and 1 that is applied to the value given to the antecedent. Usually this weight is placed equal to one so it hasn't any effect in the implication process. After, if in phase of calibration, is certificated, making the opportune iterance, that the unitary value is not opportune in order to better manage the system, it is better to modify the value of an amount that allows improving better inferential system. The implication, that is closely necessary to define for each rule, depends on the formulation of the consequent part. The system of rules that is used to construct the inferential model in examination is a much simpler one. In fact it is constituted from four rules succeeding therefore to generate a system not extremely complex but able to give good information of output (the risk index $I_{R}$ ). The system of rules adopted is the following:

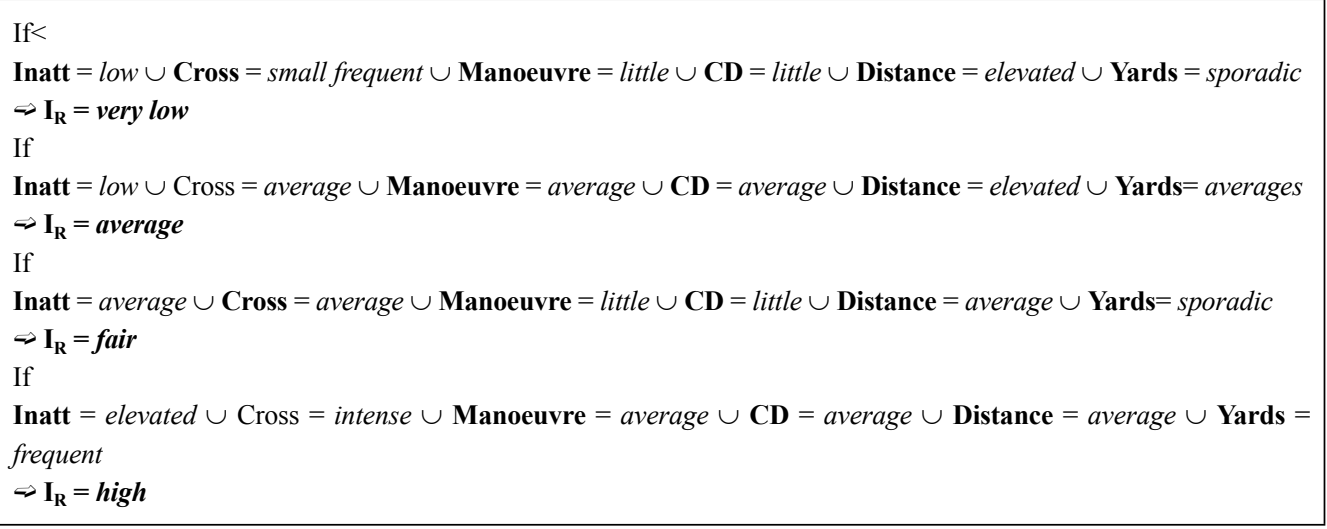

Fig. 3. System of rules to improve the inferential Fuzzy system. 
The input for the implication process is a single number generated from the antecedent, while the output value is a fuzzy set. The operations used for the implication are the some used for operator AND: the min that generates a log output fuzzy, and the prod that instead generates a weighed output. The phase of aggregation consists in joining together all the outputs of the rules and in arranging them in only one fuzzy set in order then to pass to the final phase of unfazed. The input of the aggregation process consists in the functions of output generated, from every rule, by the previous process of implication; the output consists in a fuzzy set for every variable of escape.

It can be observed that, for frequent cases of undue cross of the railroads and of presence of persons in proximity to the railway not at a safety distance, the system of rules determinates a risk index $I_{R}$ (related to safety) next to 0,5 . If $I_{R}$ is very low there are good railway safety conditions; if $I_{R}$ is high the safety conditions are poor, then we can also define a safety index $I_{S}=1-I_{R}$, that can assume the significance of the value of the module of the vector $\boldsymbol{\beta}$ of the paragraph 3 .

In other words, when the risk index increases, it can also be meant like necessity of reduction of the theoretical capacity to re-enter in suitable safety conditions previewing all those participations of servant-control previewed from the Technique "fail-safe".

\section{A study's case of the proposed method: the station of Fara Sabina in Italy}

\subsection{THE THEORETICAL CAPACITY OF THE JUNCTION}

To verify the capacity in the chosen exemplificative case (junction of Fara Sabina), we have been considered the interval of time of three hours in which the greater number of trains circulates; this interval has turned out to be the one between the 6.00 a.m. and $9.00 \mathrm{a} . \mathrm{m}$. For each of the two designs determined (without subway and with the subway) the schematic plans are shown (Fig. 4). In the same figure are represented the priority paths, determined by the compatibility's matrices for the two cases assumed, (without and with subway). It is also possible to observe that the priority paths selected aren't always independent, for example, the paths $\mathrm{AD}, \mathrm{BD}$ and $\mathrm{BE}$, in the case without subway, use the same link of railroad between switch 6 and switch 8. Similarly, with reference to the scene with the subway, the paths $\mathrm{AD}$ and $\mathrm{BD}$ use the same trait of railroad between switches 7 and 9, while paths $\mathrm{BE}$ and $\mathrm{CE}$ use both the railroad between switches 8 and 9 .

In the examined case, the anomalous time of occupation has been approximately estimated in relation to the typology of trains among them interfering, to the covered paths and to the type of central apparatus that manages the system and that strongly influences the times of interdiction between two paths5. The high frequency trains (TAF)

5 We define time of interdiction the time interval in which a route cannot be operated because it is yet formed a path incompatible with it; it is obvious that a central apparatus that guarantees elastic liberation of the paths can make the time of interdiction minor of that one of occupation. 
that interfere with the freight trains, can induce a delay that can be considered equal to the subtended area from the function of distribution of the delays until the value of $90 \%$ of the arrivals; such value $\tau$. $-\mathrm{t}_{\mathrm{i}}$, in this case, has turned out 4,33 '.

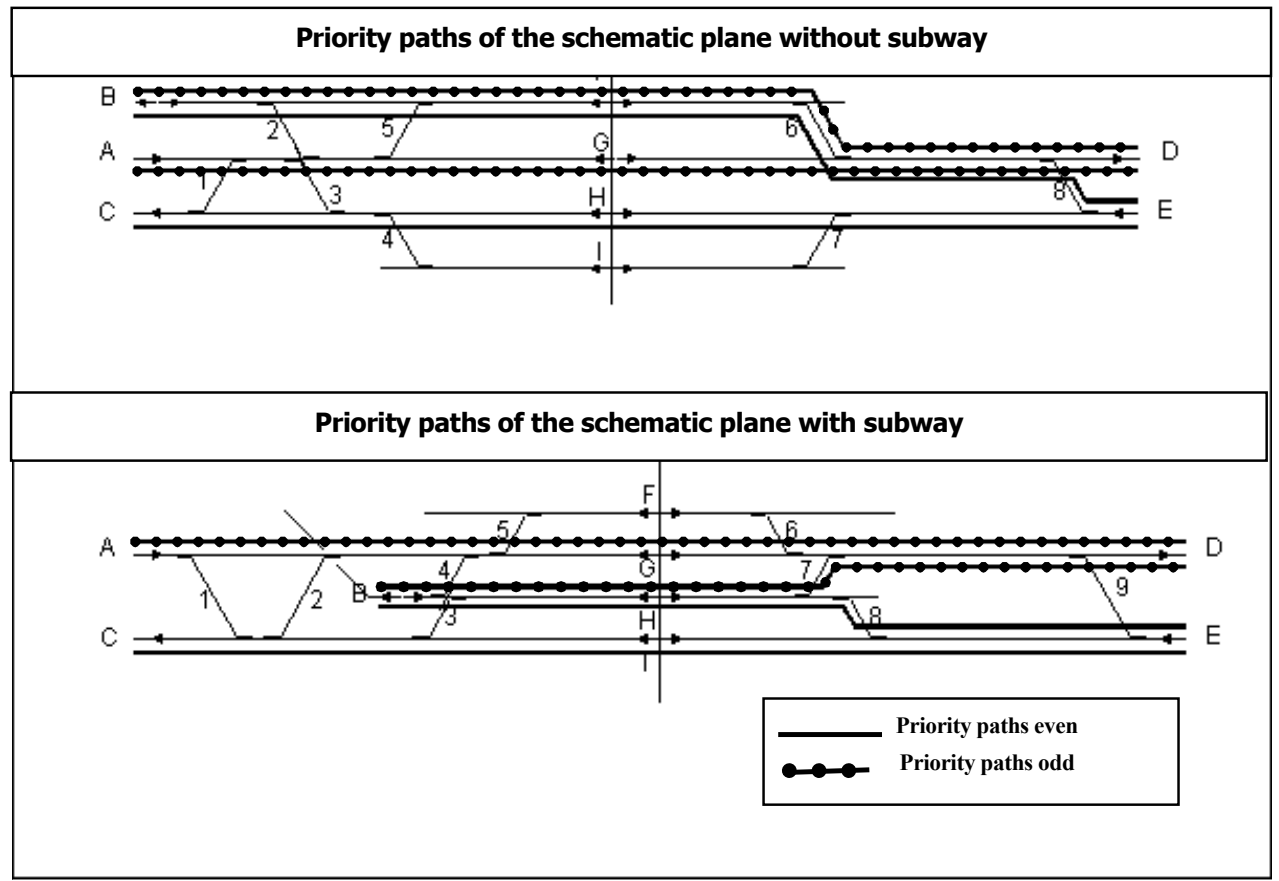

Fig. 4. Priority paths.

In Table 1 the times of regular occupation of priority paths in the two considered cases are shown.

Table 1

Times of regular occupation

\begin{tabular}{|c|c|c|c|}
\hline \multicolumn{4}{|c|}{ Time of regular occupation [min.] } \\
\hline \multirow{2}{*}{ Path } & Trains type & Without subway & With subway \\
\hline \multirow{2}{*}{ AD } & TAF & 7.82 & 7.88 \\
\cline { 2 - 4 } & FREIGHT & 5.43 & 5.57 \\
\hline \multirow{2}{*}{ BD } & TAF & 4.94 & 5.19 \\
\hline \multirow{2}{*}{ BE } & TAF & 5.74 & 5.42 \\
\hline \multirow{2}{*}{ CE } & TAF & 7.85 & 7.90 \\
\cline { 2 - 4 } & TAF & 5.57 & 5.57 \\
\hline
\end{tabular}


To gain the various functions of distribution of the arrivals, in the case of the high frequency trains (TAF) and of the freight trains, we reefer to a database called RIACE in which the timetables of effective and programmed passages of the trains in all the national net are registered.

Once gained the data relative for an entire month of service of the station of Fara Sabina (Decembers 2001), they have been separated and ordered for increasing delays of the two classes of trains examined; it is neither possible nor interesting to bring back here all the data. It's also important, as shown in Table 2, to read the parameters necessary to define the distribution functions diagram mated in Fig. 5. The scale of the two diagrams is different and, as it is obvious, the freight trains have a function of distribution of the arrivals that stretches to 0 much more slowly than that of the TAF and these have a very higher probability to arrive with a delay of a few minutes.

For the things said previously, this curves will have "to be cut" in the point in which the subtended area will be equal to 0,9 .

The delays correspondents to $90 \%$ of the arrivals are respectively 4,33' for the TAF and 160 ' for the freight trains. These are the values of the superior extreme of the external integral respectively in the cases in which they are interfered with the TAF or the freight.

Table 2

Values of the parameters necessary to define the distribution functions

\begin{tabular}{|c|c|c|c|c|c|c|}
\hline $\begin{array}{c}\text { Class of } \\
\text { trains }\end{array}$ & Surveys & $\begin{array}{c}\text { Arrivals } \\
\text { in timetable or } \\
\text { in advance }\end{array}$ & $\begin{array}{c}\text { Arrivals } \\
\text { in delay }\end{array}$ & Average $\boldsymbol{\mu}$ & Variance $\boldsymbol{\sigma}^{\mathbf{2}}$ & $\begin{array}{c}\text { Square root } \\
\text { mean }\end{array}$ \\
\hline TAF & 3275 & 2504 & 771 & 0.07 & 1.18 & 1.09 \\
\hline freight & 791 & 176 & 615 & 3.82 & 0.97 & 0.98 \\
\hline
\end{tabular}

For the location of the independent paths on which to lead the appraisals of the capacity, according to the proposed model [5], the matrix of the paths of the system, with reference to the schematic plans of station of the fig. 4, evidences that the only independent paths are the $\mathrm{BD}$ (that supports also the paths $\mathrm{AD}$ and $\mathrm{BE}$ ) inherent to the origins Rieti and Orte with destination Rome and the CE inherent to the Rome origin with destination Orte.

With regard to such paths must be therefore executed the calculation of theoretical capacity of the junction.

If the interval between the timetables of arrival of the trains is not always equal or if a train interferes with more successive trains, the interdiction probabilities must be calculated singularly for every pair consecutive trains.

It is important to observe that the presence of the subway eliminates one of the two interdictions that can effectively generate delay. 


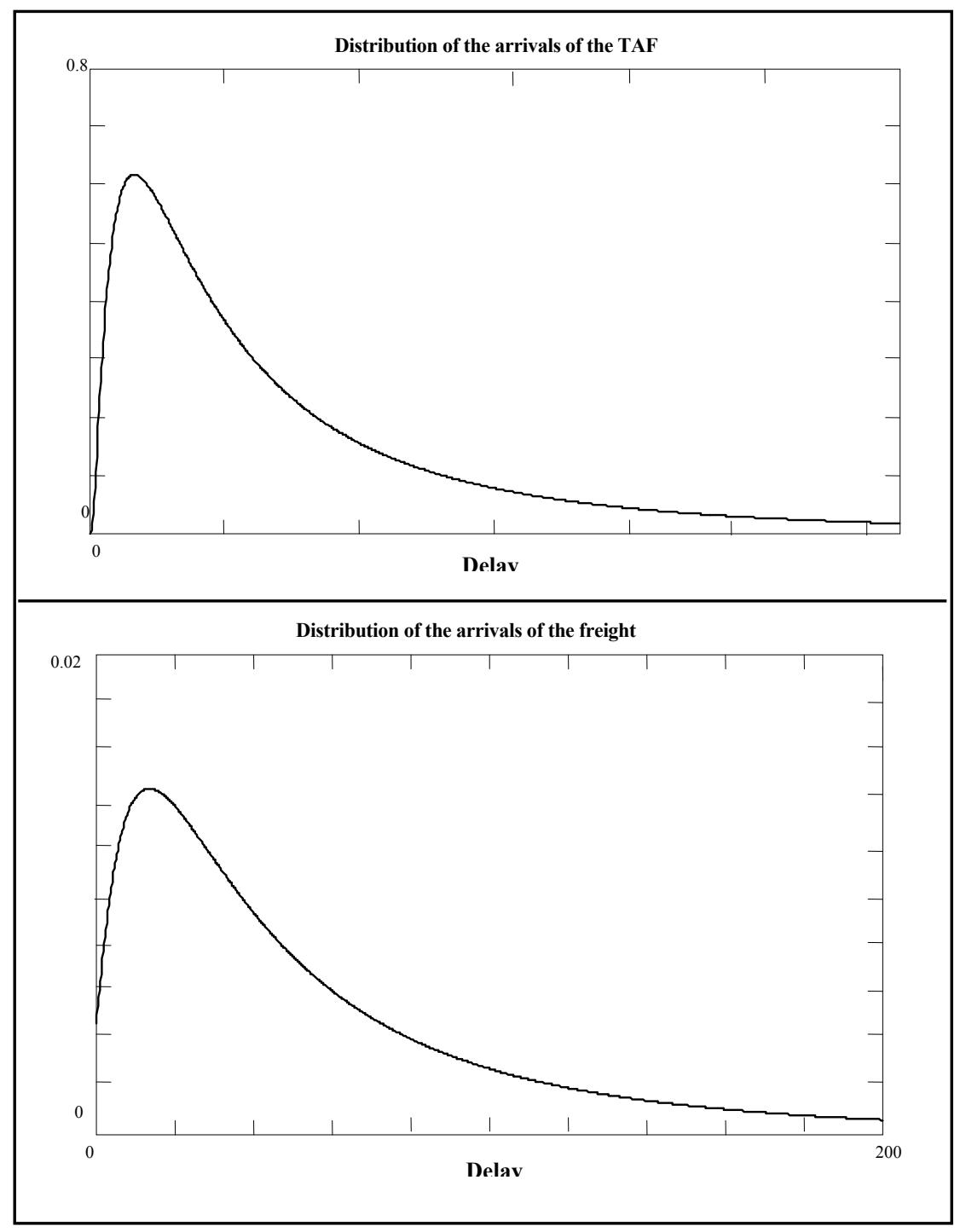

Fig. 5. Distribution of the arrivals of the TAF and freight trains.

For each one of the three interdictions we intend to study, the trains interested must be identified in the two hypotheses of cadence between Fara Sabina and Rome.

For given diagrams of distribution of the arrivals for all the trains designed with the origin in correspondence of programmed timetables of arrival.

It is, therefore, possible to estimate immediately how much is necessary to translate distribution functions and which are the pairs of trains that can interfere; for each pair of this type we must calculate the probability of interference. 
In the examined case, the freight trains can interfere with a large number of TAF and, at the same time, can be interfered. In Table 3, we can read the turns out of the calculation of the probabilities of interference between all pairs of trains present in timetable.

Table 3

Probabilities of interference between the trains

\begin{tabular}{|c|c|c|c|c|}
\hline \multicolumn{2}{|c|}{ Sum of interference probabilities between trains TAF (interfering) and freight trains (interfered) $\Sigma \mathrm{n}_{\mathrm{i}} \mathrm{P}_{\mathrm{i}}$} \\
\hline & \multicolumn{2}{|c|}{ WITHOUT SUBWAY } & \multicolumn{2}{|c|}{ WITH SUBWAY } \\
\hline & Cadence 15' & Cadence 10' & Cadence 15' & Cadence 10' \\
\hline Interdiction AD-BD & 0.238 & 0.750 & 0.238 & 0.750 \\
\hline Interdiction AD-BE & 0.454 & 0.701 & - & - \\
\hline
\end{tabular}

The exercise program previews two hypothesis of cadence for the trains TAF that use the system in the temporal period of reference $(6,00-9,00)$, every 10 or 15 minutes in both directions whatever is the type of service that it carries out (Rome - Orte, Rome - Rieti, etc.).

It is therefore enough to divide the time of reference (180') for the cadence and to multiply for 2 in order to obtain the amount of TAF that reaches and leaves between 6.00 a.m. and 9.00 a.m. from Fara Sabina: The TAF are therefore 24 in the case of cadence $15^{\prime}$ and 36 in the other.

Table 4 shows the number of trains that theoretically could circulate in the system (theoretical capacity) in the period of reference and the number of trains effectively programmed.

Table 4

Number of trains that theoretically could circulate in the system

\begin{tabular}{|c|c|c|c|}
\hline \multirow{2}{*}{$\begin{array}{c}\text { Cadence } \\
\text { [minutes] }\end{array}$} & \multicolumn{2}{|c|}{ System without subway } & \multicolumn{2}{c|}{ System with subway } & \multirow{2}{*}{ Programmed trains } \\
\cline { 2 - 3 } & \multicolumn{2}{|c|}{ Theoretical capacity [trains/T] } & \\
\hline 15 & 54 & 52 & $\mathbf{2 6}$ \\
\hline $10^{\prime}$ & 59 & 55 & 38 \\
\hline
\end{tabular}

The values found are next to those obtainable with other methodologies of analysis (U.I.C. etc), but differently from these, the tested model allows to hold account, in interpretative shape, of the effect of the single factors that influence the capacity and establish the proportions of the station plans, the systems and devices to be used for the freeing of the paths and the conditions of exercise as the succession of the trains in arrival or departure.

In effect, the theoretical capacity of the system couldn't ever be caught up also because, how is the configuration (with or without subway) or the organization of the 
succession of the trains in timetable, it turns out impossible to saturate completely the paths in order to hold account, opportunely, of the safety conditions. In fact, increasing the coefficient of utilization of the junction, the exposure to the risk factors increases, in a generalized manner, and therefore the conditions of safety of the system will reduce.

\section{THE PRACTICAL CAPACITY OF THE JUNCTION IN SAFETY CONDITIONS}

In the previous paragraph both cases of system without subway and with subway has been taken inconsideration. The realization of a subway, obviously, increases the level of safety of the cross of the railway junction and, in particular, reduces the exposure level of two associate reasons: the undue cross and the distance of safety from the railroads, both generating elevated level of dangerousness.

Therefore the practical capacity, computable placing $I_{S}=|\beta|=1-I_{R}$, in the case without subway is reduced a lot more than in that with subway where better conditions of exercise safety will occur.

The values of the practical capacities in table 5 are based on the appraisal of the linguistic variables of input that can be synthesized in the following table 6 :

Table 5

Practical Capacity

\begin{tabular}{|c|c|c|}
\hline \multirow{2}{*}{ Cadence } & \multicolumn{2}{|c|}{ Practical Capacity [trains/T] } \\
\cline { 2 - 3 } & System without subway & System with subway \\
\hline 15, & $27\left(\mathrm{I}_{\mathrm{S}}=0.493\right)$ & $36\left(\mathrm{I}_{\mathrm{S}}=0.693\right)$ \\
\hline 10, & $29\left(\mathrm{I}_{\mathrm{S}}=0.493\right)$ & $38\left(\mathrm{I}_{\mathrm{S}}=0.693\right)$ \\
\hline
\end{tabular}

Table 6

Degree of belongings of the function of membership

\begin{tabular}{|c|c|c|}
\hline \multirow{2}{*}{ Associated reason to the accident } & \multicolumn{2}{|c|}{$\begin{array}{c}\text { Degree of belongings of the function } \\
\text { of membership }\end{array}$} \\
\cline { 2 - 3 } & System without subway & System with subway \\
\hline Inattention travellers and staff FS (Inatt) & average /elevated & low \\
\hline Undue cross of the railroads (Crosses) & average/intense & little frequent \\
\hline Irregular movements of manoeuvre (Manoeuvre) & little & little \\
\hline Undue climb/downhill from train (CD) & little & little \\
\hline $\begin{array}{c}\text { Persons on the railway not at a safety distance } \\
\text { (Distance) }\end{array}$ & elevated \\
\hline $\begin{array}{c}\text { Abnormality regarding the operating staff of job } \\
\text { (Yards) }\end{array}$ & low & low \\
\hline
\end{tabular}




\section{Conclusions}

With an approach based on the technique of fuzzy sets, it is turned out the possibility to establish the numerical value of the practical capacity with reference to the logical relations - qualitative between the characteristics of the system and potential conditions of risk. Such approach has concurred to characterize the module of an opportune vector $\boldsymbol{\beta}$, inferior to the unit, of employ of theoretical capacity in conditions of maximum reliability of the system. In such a way, once determined the theoretical capacity of a railway junction in different planning conditions of the system, by means of suitable analysis of the railway accident's frequency in Italy in the last years, it's been possible to describe the logical connection between factors of risk and achievable accident's events. Consequently we can find the practical capacity of the junction in both the predicted different planning situations and in optimal conditions for the safety.

It is also evidenced, with exemplificative reference to the case in study, that for different planning configurations of the junction, even if similar values of the theoretical capacity are turned out, very different appraisals are obtained on the practical capacity in reason of the qualitative relations with the potential risk factors. The use of the exposed methodology, in different alternatives, permits to choice the best solution in the outline of the safety and, therefore the optimisation of the interventions in devising the elements of the station's plane. From the presented methodological approach are possible some future extensions to other fields of infrastructures planning, i.e. airports or other punctual multimode infrastructures in different situations as a tool for optimising the conditions of the safety in a different plan design or exercise's conditions.

\section{REFERENCES}

1. F. Corriere, D. Di Vincenzo, The Rail Quality Index as an indicator of the Global Comfort in optimizing safety, quality and efficiency in railway rails. Procedia - Social and Behavioral Sciences, Volume 53, Pages 622-632, Elsevier, ISSN: 1877-0428, October 2012.

2. A. Landex, Evaluation of Railway Networks with Single Track Operation Using the UIC 406 Capacity Method, Networks and Spatial Economics, Volume 9, Issue 1, pp 7-23, DOI 10.1007/s11067-0089090-7, March 2009.

3. Y.-J. Zheng, X.-C. Zhang, B. Xu, L.-L, Wang, Carrying Capacity Reliability of Railway Networks, Journal of transportation systems engineering and information technology, volume 11, issue 4, 16-21, ISSN:1009-6744, august 2011.

4. T.J. Mlinarić, K. Ponikvar, Energy Efficiency of Railway Lines, Vol. 23, No 3 (2011), Promet - Traffic\&Transportation, Vol. 23, No. 3, 187-193, 2011.

5. F. Corriere, R. Biondo, G. Sciume, The choice between alternative solutions in uncertain conditions: the use of a suitable fuzzy methodology as a tool for the project optimisation of the railway junction. Proceedings of V international Conference of stochastic geometry, convex bodies, empirical measures $\&$ applications to engineering, medical and earth sciences, pp. 175-201. Palermo, 6-11, Settembre 2004.

6. F. Corriere, Sulla Potenzialità dei sistemi di trasporto in sede propria, Ingegneria Ferroviaria, Gennaio - Febbraio 1982. 
7. F. Corriere, Potenzialità. e regolarità di esercizio delle linee ferroviarie, Ingegneria Ferroviaria, Gennaio - Febbraio 1984.

8. L. Florio, G. Malavasi, E. Salvini, Analisi dei ritardi e verifica di un nodo ferroviario complesso, Ingegneria Ferroviaria - Agosto 1985.

9. A.H.S. Ang, W.H. Tang, Probability concepts in Engineering Planning and design, Volume I - John Willey \& Son - N.Y. - 1975.

10. H. Mabrouk, A. Stuparu, B. Charreton, Exemple de typologie d'accidents dans le domaine des transports guidés, Revue Générale des Chemins de Fer n. 3 (pp. 17-25), 1998.

11. M. Guerrieri, G. Parla, D. Ticali, F. Corriere, Tramway Track: a new Approach for Measuring the Transverse Profile of Worn-Out Rails - AASRI Procedia, Elsevier. Proceedings of the Conference on Modelling, Identification and Control, Singapore, December 30-31, 2012.

12. A.P. Cucala, A. Fernández, C. Sicre, M. Domínguez, Fuzzy optimal schedule of high speed train operation to minimize energy consumption with uncertain delays and drivers behavioral response, Engineering Applications of Artificial Intelligence, Volume 25, Issue 8, Pages 1548-1557, December 2012.

13. H.J Zimmermann, Fuzzy Set Theory and its applications, Kluwer Academic Publishers, Boston/ Dordrecht/London, 1994.

14. H. Mabrouk, A. Stuparu, B. Charreton, Exemple de typologie d'accidents dans le domaine des transports guidés, Revue Générale des Chemins de Fer n. 3-pagg 17-25, 1998.

Received: 26.11.2012

Revised: 25.02 .2013 